Article

\title{
Bioceramic Layers with Antifungal Properties
}

\author{
Daniela Predoi ${ }^{1, *}$, Simona Liliana Iconaru ${ }^{1}$ and Mihai Valentin Predoi ${ }^{2}$ \\ 1 National Institute of Materials Physics, Atomistilor Street, No. 405A, P.O. Box MG 07, Magurele 077125, \\ Romania; simonaiconaru@gmail.com \\ 2 Department of Mechanics, University Politehnica of Bucharest, BN 002, 313 Splaiul Independentei, Sector 6, \\ Bucharest 060042, Romania; predoi@gmail.com \\ * Correspondence: dpredoi@gmail.com; Tel.: +40-21-241-81-54
}

Received: 11 July 2018; Accepted: 3 August 2018; Published: 8 August 2018

check for updates

\begin{abstract}
The sol-gel method was used to synthesize the silver doped hydroxyapatite (Ag:HAp) gels in order to produce the antifungal composite layers. The pure Ti disks were used as the substrate for the composite layers. Important information about suspensions used to make Ag:HAp composite layers were obtained from an ultrasonic technique. The identification of the phase composition of the Ag:HAp composite layers was accomplished X-ray diffraction (XRD). The morphology and the thickness of the layers was evaluated using scanning electron microscopy (SEM). The uniform distribution of the constituent elements ( $\mathrm{Ag}, \mathrm{Ca}, \mathrm{P}$, and $\mathrm{O}$ ) in both analyzed samples was observed. The antifungal activity of the samples against Candida albicans ATCC 10231 microbial strain were investigated immediately after their preparation and six months later. SEM and confocal laser scanning microscopy (CLSM) images showed that the composite layers at the two time intervals exhibited a strong antifungal activity against Candida albicans ATCC 10231 and completely inhibited the biofilm formation.
\end{abstract}

Keywords: hydroxyapatite; silver; layer; antifungal properties

\section{Introduction}

The current medical practices in various medical fields involves the use of implants and indwelling medical devices. In recent years, a rising number in the apparition of implant-related infections has been noticed because of the increase in the use of implants in medicine. These facts have accentuated the pressing need to work towards developing new implants less susceptible to infections. Over the last decades, measures have been implemented to reduce the number of implant related infections by defining and putting into effect strict hygienic routines in the operating rooms and by using perioperative antibiotic prophylaxis [1-9]. Nevertheless, because the incidence of implant-related infections has continued to increase, the attention of scientists has focused on the development of newly biocompatible and antimicrobial materials that can be used as coatings for implantable medical devices [10,11]. In the last years, various types of materials have been proposed to be used as biomaterial coatings, but the most representative, has been widely accepted as being the hydroxyapatite (HAp). HAp belongs to the family of calcium phosphate ceramics and due to its similarity with the human hard tissue and its remarkable properties such as biocompatibility, bioactivity, porosity, and osteoconductivity it has been used for bone reconstructions, as a coating material for hip and knee prosthesis, for bone reconstructions, for tissue engineering, as filler in dental prosthesis, etc. [12-15]. Nonetheless, previous studies have reported that, hydroxyapatite coatings are not antimicrobial and are more likely to assist the development of microbial biofilms. In this context, the use of an antimicrobial agent such as silver, zinc, cooper, or cerium ions embedded in the hydroxyapatite matrix has been proposed. The most representative antimicrobial effects have been reported in the case of silver doped hydroxyapatite nanopowders (Ag:HAp) and implicitly in the case of Ag:HAp coatings [12-18]. 
Since ancient times, the antibacterial effects of silver salts have been observed [19,20], and nowadays silver is one of the most used antimicrobial agents. Silver ions are been utilized to control bacterial growth in a variety of applications, such as dental work, catheters, implant related infections, and burn wounds. Recent studies have emphasized that silver exhibits strong biocidal effects on as many as 16 species of bacteria including gram-positive, gram-negative bacterial strains, as well as fungal strains [21-25]. Even though the antimicrobial effects of silver ions are well known and utilized in a wide range of applications, their mechanism of actions have not been yet fully understood [23-28].

Taking into consideration the existing studies, the antimicrobial activities of silver ions can be attributed to the following mechanisms: they could produce damage to bacterial membranes, have the ability to inhibit their DNA replications, protein synthesis, and enzymatic activity and are also responsible for the alteration of cell respiration [29-33]. Moreover, an extremely rare microbial resistance to silver compounds which suggests the presence of various antimicrobial mechanisms acting in synergy has been reported [34]. Besides the antimicrobial properties, great attention has been focused on the osteogenic activities of silver ions. The results reported in the literature have highlighted that osteogenic activities of silver nanoparticles are strongly dependent on the silver concentration, incubation time, and physical properties of the materials [35]. Kim et al. [36], in their studies, found that the diameter of silver nanoparticles was negatively correlated with the cytotoxic effect and antimicrobial properties, while the studies reported by Hussain et al. [37] highlighted a positive correlation between the size of the nanoparticles and the cytotoxic effects, suggesting that the cytotoxic effects could be strongly dependent on other parameters. Furthermore, Qin et al. [38] investigated the influence of silver nanoparticles on the osteogenic activities of urine-derived mesenchymal stem cell (MSCs) and their results revealed that for a concentration of AgNPs $\leq 4 \mu \mathrm{g} / \mathrm{mL}$ the cell viability wasn't significantly influenced. In accordance with the previously reported results of Qin et al. [38], Mahmood et al. [39] have shown in their studies that several types of compounds containing silver nanoparticles are able to stimulate the mineralization of MC3T3-E1 cells by increasing osteogenic gene expression.

The most common microbial strains involved in implanted related infections are staphylococci, with the nosocomial pathogen Staphylococcus aureus and fungal pathogens, Candida albicans. Both S. aureus and C. albicans are well known for their ability to form biofilms [3,40-43]. It has been reported, and it is widely accepted that the biofilm formation has an important contribution to the development of implant related infections because biofilms are communities of adherent microorganism and are characterized by resistance to commonly used antimicrobial drugs [43-45]. Biofilm-associated infections are most difficult to treat since they exhibit an increased resistance to conventional antibiotic and antimycotic agents. Candida albicans is an opportunistic fungal pathogen that colonizes both human mucosal and biomaterial surfaces [46,47]. Candida are the fungi cells most often isolated from implantable medical devices, such as catheters, prostheses, etc. The presence of biofilms exhibit a great resistance to conventional antifungal agents and contributes to the persistence of infection. In this case, both substrate and surface coatings have an important role in the development of fungal biofilm. In the last years, titanium has been considered the high-end standard for implantable devices due to its outstanding properties $[48,49]$.

Therefore, this study focuses on the development of biocompatible coatings with antifungal properties on titanium substrates. The spin-coating technique was used to prepare the Ag:HAp composite layers from stable gels. The stability of synthesized gels by the sol-gel method was evaluated by ultrasonic measurements. Ultrasonic methods have been used in the last decades in order to characterize particulate systems, methods described in detail in the classical textbooks of Povey [50] or Dukhin and Goetz [51]. Such characteristics, like particle size and stability, are correlated to ultrasounds attenuation in the suspensions as presented in recent results review by Povey [52]. We suggest, in this paper, a relatively simple and efficient experimental technique, capable to quantitatively asses the suspension stability using ultrasounds in dynamic regime. The prepared Ag:HAp composite layers were characterized by X-ray diffraction (XRD) and scanning 
electron microscopy (SEM). To evaluate the stability of the biological properties over time of Ag:HAp composite layers the cytotoxicity and antifungal activity of the samples were investigated immediately after their preparation and again in the same conditions six months later. The effects of the composite layers on the morphology of $C$. albicans fungal cells at the two time intervals were investigated by SEM and confocal laser scanning microscopy (CLSM). The novelty provided by this article compared with previous reported studies [53-55] involves both the use of a nondestructive investigation technique for the characterization of the stability of synthesized gels by sol-gel, as well as the study regarding the stability of the biological activity of Ag:HAp-S1 and Ag:HAp-S2 composite layers in time.

\section{Materials and Methods}

\subsection{Sample Preparation}

\subsubsection{Materials}

The reagents such as calcium nitrate $\left[\mathrm{Ca}\left(\mathrm{NO}_{3}\right)_{2} \cdot 4 \mathrm{H}_{2} \mathrm{O}\right.$, Sigma-Aldrich, St. Louis, MO, USA], triethyl phosphite (TEP), $\mathrm{P}\left(\mathrm{C}_{2} \mathrm{H}_{5} \mathrm{O}\right)_{3}$, silver nitrate $\left(\mathrm{AgNO}_{3}\right)$ (Alfa Aesar, Karlsruhe, Germany; 99.99\% purity), ammonium hydroxide $\left(\mathrm{NH}_{3}\right)$ (25\%, Alfa Aesar, Karlsruhe, Germany; $99.99 \%$ purity) and ethanol were used for the obtained of silver doped hydroxyapatite (Ag:HAp) solutions by sol-gel method.

\subsubsection{Layers of Silver Doped Hydroxyapatite Preparation}

Silver doped hydroxyapatite, $\mathrm{Ca}_{10-x} \mathrm{Ag}_{x}\left(\mathrm{PO}_{4}\right)_{6}(\mathrm{OH})_{2}$, (Ag:HAp) layers were prepared conformable to the method presented by Kim et al. in their studies [56]. The composition ratio, $[\mathrm{Ca}+\mathrm{Ag}] / \mathrm{P}$, in the Ag:HAp sol was arranged to be equal to 1.67 according to research presented in [57]. In order to obtain the complex material which was afterwards deposited by the sol-gel dip coating method on a pure Ti substrate, triethyl phosphite (TEP), $\mathrm{P}\left(\mathrm{C}_{2} \mathrm{H}_{5} \mathrm{O}\right)_{3}, 1 \mathrm{M}$, and silver nitrate $\left(\mathrm{Ag}\left(\mathrm{NO}_{3}\right)_{6} \cdot 6 \mathrm{H}_{2} \mathrm{O}\right)$ were dissolved in ethanol. After adding deionized water, the solution was continuously stirred for $24 \mathrm{~h}$ at $40^{\circ} \mathrm{C}$. Afterwards, to the solution containing P and $\mathrm{Ag}$, a $\mathrm{NH}_{4} \mathrm{OH}$ solution ( 5 vol. $\%$ ) was added. At the same time, in a beaker with ethanol, a stoichiometric amount of calcium nitrate $\left(\mathrm{Ca}\left(\mathrm{NO}_{3}\right)_{2} \cdot 4 \mathrm{H}_{2} \mathrm{O}\right)$ was dissolved and stirred for $24 \mathrm{~h}$ at $40{ }^{\circ} \mathrm{C}$. In the solution containing $\mathrm{Ag}$ and $\mathrm{P}$, the solution containing Ca was added drop by drop. The resulted Ag:HAp gels after aging, S1 (mixture stirred a $72 \mathrm{~h}$ at $40^{\circ} \mathrm{C}$ ) and S2 (mixture stirred a $72 \mathrm{~h}$ at $100{ }^{\circ} \mathrm{C}$ ) were used to prepare the Ag:HAp-S1 and Ag:HAp-S2 composite layers by spin-coating technique. Before coating the pure Ti disks used as substrate were cleaned in ultrasonic bath with acetone and subsequently ethanol and bi-distilled water. The coating process was carried out at a speed of $2000 \mathrm{rpm}$ by centrifugation for $60 \mathrm{~s}$. Next, the pure Ti disks coated with a composite layers (Ag:HAp-S1 and Ag:HAp-S2 ) were dried for $60 \mathrm{~min}$ at $100^{\circ} \mathrm{C}$. Spin-coating and dried procedures were repeated 3 times. Finally, the Ag:HAp-S1 and Ag:HAp-S2 composite layers were thermally treated for $12 \mathrm{~h}$ at $300{ }^{\circ} \mathrm{C}$ (with heating rate of $1{ }^{\circ} \mathrm{C} / \mathrm{min}$ ) in order to obtain films with a crystalline structure and to remove the solvents [58]. On the other hand, the resulted sol-gel solutions, $\mathrm{S} 1$ (mixture stirred a week at $40^{\circ} \mathrm{C}$ ) and $\mathrm{S} 2$ (mixture stirred a week at $80^{\circ} \mathrm{C}$ ) used to prepare the Ag:HAp-S1 and Ag:HAp-S2 composite layers by spin-coating technique were analyzed for the first time by ultrasonic measurements in order to highlight the stability of these solutions. This technique monitors one of the recorded ultrasonic echoes, providing a dynamic parameter associated to the suspension stability.

\subsection{Ultrasonic Measurements}

The experiments took place in a specialized laboratory, using two identical ultrasonic transducers H5K (GE's Krautkramer, GE, Boston, MA, USA) of $5 \mathrm{MHz}$ central frequency. The two transducers are coaxially leak-proof inserted in the Perspex box holding the investigated fluid (Figure 1a). The first transducer is generating the ultrasonic chirp in the fluid, as the Pulser-receiver, JSR Ultrasonics 
DPR300 (Imaginant Inc., Pittsford, NY, USA) is applying the short electrical impulse. This transducer receives then, all the successively reflected acoustic signals. The second transducer is only receiver, for the first direct signal and then for all the multiply reflected signals. The Pulser-receiver is amplifying the electrical signals from both transducers and sends these signals to a digital Tektronix DPO 4014B oscilloscope (Tektronix, Inc., Beaverton, OR, USA) [59]. An accurate proprietary digital thermometer is measuring the fluid temperature (Figure 1b). The signals are digitally recorded and processed using a proprietary software.

a)

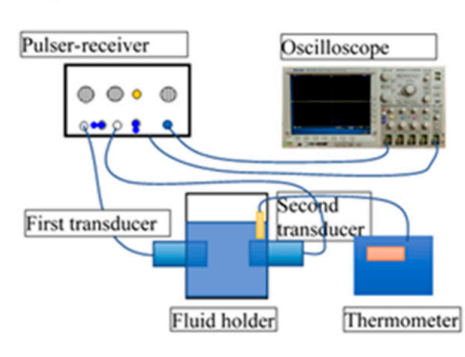

Figure 1. Experimental setup: Schematics (a) and image (b).

\subsection{Structural and Morphological Characterizations}

The X-ray diffraction (Bruker, Karlsruhe, Germany) were used to investigate the structure of Ag:HAp-S1 and Ag:HAp-S2 layers after thermal treated in air for $60 \mathrm{~min}$ at $500{ }^{\circ} \mathrm{C}$. The crystalline phases of the prepared Ag:HAp-S1 and Ag:HAp-S2 composite layers were established using Bruker AXS D8 Focus diffractometer (Bruker, Karlsruhe, Germany) with a LynxEye detector using Cu K $\alpha$ radiation $(\lambda=1.5418 \AA)$. The data were collected in the $2 \theta$ range of $20^{\circ}-80^{\circ}$, with a step size of $0.02^{\circ}$ and time per step $20 \mathrm{~s}$. The homogeneity and morphology of the layers deposited on pure Ti were studied by scanning electron microscopy (SEM) using a Hitachi S-4500 microscope (Hitachi High Technologies America, Inc., Schaumburg, IL, USA) equipped with an X-ray Energy Dispersive Spectroscopy (EDX) system which allowed analysis of elemental compositions.

\subsection{Antifungal Assay}

The antifungal activity of the Ag:HAp-S1 and Ag:HAp-S2 composite layers obtained by spin-coating technique was investigated using Candida albicans ATCC 10231 microbial strain. To evaluate the stability of the biological properties over time of Ag:HAp-S1 and Ag:HAp-S2 composite layers, the in vitro experiments on antifungal activity of the samples were investigated immediately after their preparation (Ag:HAp-S1_T0 and Ag:HAp-S2_T0) and again in the same conditions 6 months later (Ag:HAp-S1_T6 and Ag:HAp-S2_T6). The qualitative antifungal assays were performed using microbial suspensions obtained from $24 \mathrm{~h}$ solid cultures in liquid yeast peptone glucose (YPG) medium. Afterwards, the cultures were transferred to Muller Hinton agar (MHA) and incubated to reach an exponential growth phase. The microbial suspensions were adjusted to $0.5 \mathrm{McF}$ arland standard $\left(1 \times 10^{6} \mathrm{CFU} / \mathrm{mL}\right)$ and the Ag:HAp-S1_T0, Ag:HAp-S2_T0, Ag:HAp-S1_T6 and Ag:HAp-S2_T6 were placed aseptically and distinctively onto the inoculated MHA plates. The agar plates were incubated at $37^{\circ} \mathrm{C}$ for $18-24 \mathrm{~h}$ and the diameter of the inhibition zones that were formed were measured in $\mathrm{mm}[60,61]$. The experiments were performed in triplicate.

The antifungal activity of the Ag:HAp-S1 and Ag:HAp-S2 composite layers obtained by spin-coating technique was quantified at $24 \mathrm{~h}$. For this purpose, C. albicans ATCC 10231 ( $500 \mu \mathrm{L}$ of 0.5 McFarland microbial suspension in sterile saline obtained from $24 \mathrm{~h}$ microbial cultures) was grown on the samples immersed in YPG. After 24 h, the Ag:HAp-S1_T0, Ag:HAp-S2_T0, Ag:HAp-S1_T6 
and Ag:HAp-S2_T6 composite layers were removed from the culture medium and washed using sterile saline solution in order to remove the non-adherent yeast cells. The composite layers were then introduced into sterile saline $(1 \mathrm{~mL})$, vortexed for suspending the microbial cells embedded in the biofilm formed on the surface, washed in saline solution, fixed in cold methanol, and prepared for confocal laser scanning microscopy (CLSM) examination. For the CLSM observation, the microbial cells were stained for $5 \mathrm{~min}$ with propidium iodide (PI), washed 2 times with water; air dried and then visualized in reflection and fluorescence modes using a TCS SP confocal microscope, having a 10X HCX PL objective, and a numerical aperture NA of 0.3. An Ar ion laser $(488 \mathrm{~nm})$ was used to acquire both reflection and fluorescence. The reflection image was depicted in green in the CLSM images while the fungal cells dyed with PI were depicted in red. Propidium iodide (PI) is one of the most popular red-fluorescent nuclear and chromosome counterstain and is widely used in a variety of biological related methods of investigation such as fluorescence microscopy, confocal laser scanning microscopy, flow cytometry, and fluorometry, etc. It binds to double stranded DNA by intercalating between base pairs. Because this fluorescent intercalating agent is not permeant to live cells, PI, is also used to detect dead cells in a population. Propidium iodide cannot cross the membrane of live cells, thus making it very useful for differentiating between necrotic, apoptotic and healthy cells. PI is excited at $488 \mathrm{~nm}$ and, with a relatively large Stokes shift, and emits at a maximum wavelength of $617 \mathrm{~nm}$. The use of PI in the CLSM observation allowed us to observe the fungal cells adhered on the surface of Ag:HAp-S1 and Ag:HAp-S2 composite layers (the fungal cells are marked in red in the CLSM images).

Scanning electron microscopy (SEM) was also used in order to evaluate C. albicans cell morphology. For the SEM observation, C. albicans cells were fixed on the thin films by staining them with $200 \mu \mathrm{L}$ cold absolute methanol for approximately $5 \mathrm{~min}$. The excess of methanol was removed and the samples were air dried before visualization. The SEM observation was done using a HITACHI S4500 microscope. For both SEM and CLSM observation, three individual experiments using the same conditions have been performed.

\subsection{Cytotoxicity Assay}

The investigation regarding the cytotoxicity of the Ag:HAp-S1 and Ag:HAp-S2 composite layers obtained by spin-coating technique was effectuated using primary human osteoblast cells obtained from the upper part of patient's femur The primary osteoblast culture cells from bone explants were prepared according to Gallagher et al. protocol [62]. The bone tissue has been detached from the soft conjunctive tissue and was transferred into a sterile recipient with phosphate buffered saline (PBS). The cells were afterwards grown in Dulbecco Modified Eagle's Medium (DMEM) supplied with 10\% fetal bovine serum, DMEM sodium pyruvate, $2 \%$ glutamine and an antibiotic mix. Next, the osteoblast cells were placed in DMEM enriched with antibiotics, washed successively using antibody solutions and cultivated for 7-10 days in DMEM medium containing 15\% Bovine Serum Albumin (BSA), 2\% glutamine and buffered with natrium bicarbonate. After osteoblast culture achievement, the cells were treated with trypsin $0.05 \%$ and spited in Petri dishes. The osteoblast cells were then seeded at a density of $10^{5}$ cells $/ \mathrm{mL}$ in Petri dishes and incubated on the Ag:HAp-S1 and Ag:HAp-S2 composite layers for $24 \mathrm{~h}$. After $24 \mathrm{~h}$, the samples were investigated using fluorescence microcopy with an Olympus IX71 microscope (Olympus, Tokyo, Japan). For the visualization of the adhered cells, the Ag:HAp-S1 and Ag:HAp-S2 composite layers were washed three times with phosphate saline buffer and one time using a $2 \%$ bovine serum albumin in $0.1 \%$ Triton X-100. Afterwards a $2 \mu \mathrm{g} / \mathrm{mL}$ phalloidin coupled with FITC in 1.2 bovine serum albumin solution was added. The samples were kept in the dark one hour and then washed before observation.

\subsection{Statistical Analysis}

All the biological investigations were carried out in triplicate. The statistical analysis was carried out using the $t$-test and analysis of variance (ANOVA). The difference established between samples was appreciated to be significant at $p<0.05$. 


\section{Results and Discussions}

Important information about Ag:HAp (S1 and S2) gels used to prepare the Ag:HAp-S1 and Ag:HAp-S2 composite layers were obtained from ultrasound measurements. We chose this characterization technique due to the inconveniences associated with common techniques, such as dynamic light scattering (DLS) or $\zeta$-potential, because ultrasound measurements have the major advantage of propagation through concentrated opaque suspensions. Ultrasound measurements allowed us to obtain information on the stability of resulted gels Ag:HAp (S1 and S2) after being stirred for $15 \mathrm{~min}$ at room temperature without dilution. During ultrasonic measurements, five to seven echoes were recorded every $5 \mathrm{~s}$, depending on the signal-to-noise ratio. The recorded signals of samples S1 and S2 are shown on Figure 2, beginning with the second echo, which is not amplitude saturated.

The first signal that was recorded was the direct signal between the first transducer and the second transducer. The first transducer is the signal generator and the second transducer is just a reception transducer. The distance between the transducers was chosen to be equal to $d=25 \mathrm{~mm}$. The other signals represent the successive echoes detected by the two transducers, as the short signal is reflected by the circular surfaces of the transducers and moves along the distance between these surfaces. In this study, double distilled water was chosen as the reference.

a)

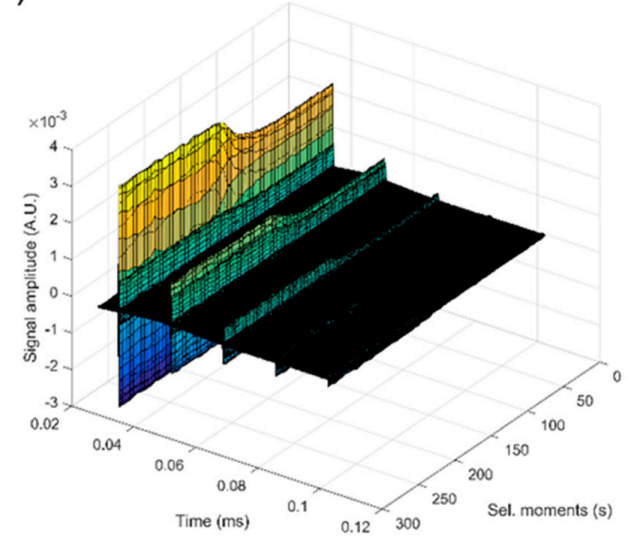

b)

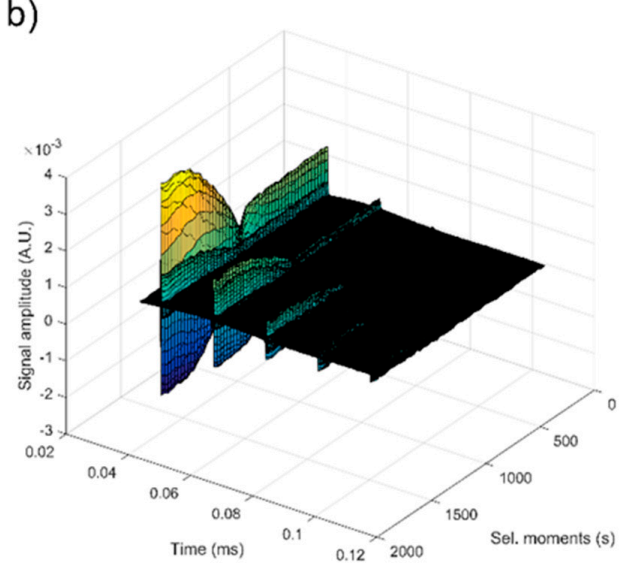

Figure 2. The recorded signals of samples S1 (a) and S2 (b).

For each Ag:HAp gels resulting after agitation for $15 \mathrm{~min}$ at room temperature, the first recorded chirp was amplified until saturation of the amplifier. The first recorded chirp which represents the direct signal arrives after approximately $0.017 \mathrm{~ms}$. The goal was to record five echoes for each sample regardless of the degree of attenuation. In order to apply the method, the examination was focused on the second echo, since the first one is too strong and saturated the amplifier. The same second echo was selected for each of the two resulting Ag:HAp gels (S1 and S2) and is presented on Figure 3.

As can be seen in Figure 3, the two samples (S1 and S2) showed a different behavior. The axis representing the recording moments is different for the two samples, from 300s (S1) to 1600 (S2). Each sample indicates a bulk precipitation period, during which the signal amplitudes changes slowly and linearly. Then comes a relatively rapid transition period, during which the separation surface between precipitating suspension and solvent, passes in front of the transducers. The last period represents the slow asymptotic evolution towards the pure solvent. The variation of the signal amplitude during the first period is not identical for the two samples (Figure 4).

Sample S1 has a linear increase of amplitude during $100 \mathrm{~s}$ (Figure 4a). The sample S2 exhibited a linear decrease of amplitudes during the first period. Sample $\mathrm{S} 2$ has a rapid decrease of amplitude during the transition period, followed by a slow increase (more than $400 \mathrm{~s}$ ) of the amplitude towards the stable state. This phenomenon is explained by a possible particle concentration in front of the 
separation surface, coupled with a significant variation of the acoustic wave velocity, from the value of the velocity in the suspension to the value in the solvent.

a)

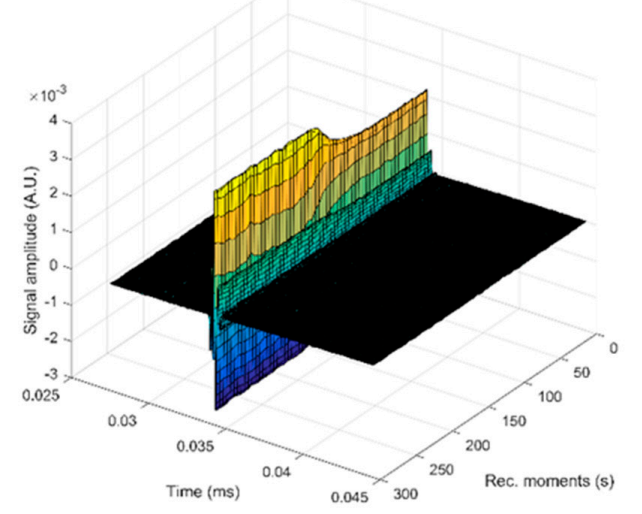

b)

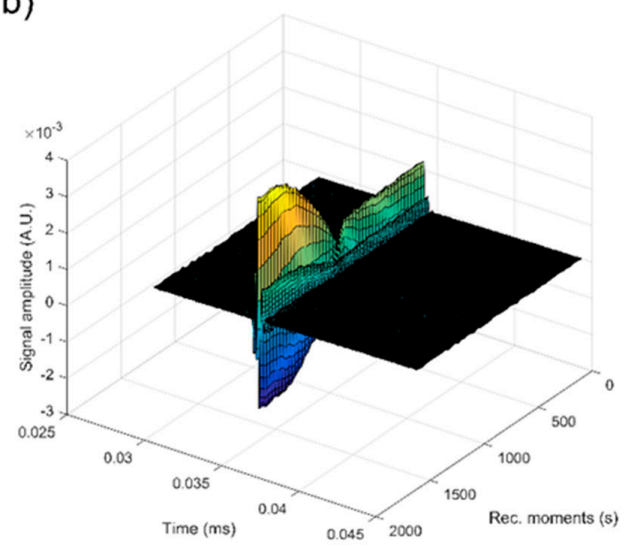

Figure 3. The same second echo selected for investigation for samples S1 (a) and S2 (b).

a)

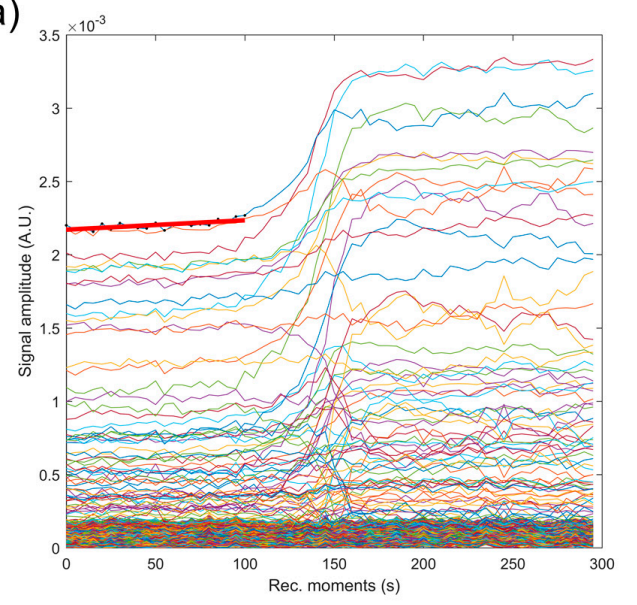

b)

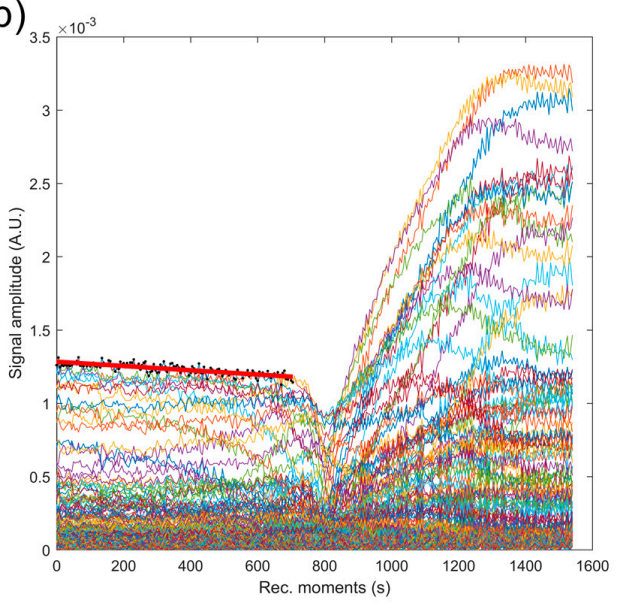

Figure 4. Evolution in time of the amplitudes of the selected echo, for the samples S1 (a) and S2 (b).

The most significant parameter, defining stability of the suspension is the amplitude variation during the initial period and the duration of this period. It is essential to specify that the amplitude variation can be manifested by its decrease or increase due to the dispersion of the acoustic waves. Therefore, the absolute value will be a measure of stability. The measured value of the signal amplitude is directly influenced by both the applied voltage on the transducer and amplification. As a result, the slope of the amplitude-time function will be normalized by the average amplitude during the stage. We suggest using a stability parameter, measured in $\mathrm{s}^{-1}$ and defined as:

$$
s=\frac{1}{A_{m}}\left|\frac{\mathrm{d} A}{\mathrm{~d} t}\right|
$$

The absolute values of the amplitudes of the second echo for the two investigated samples are presented on Figure 4. For the first period of each sample, a linear best fit, marked by a red line indicates the method used to compute the stability Parameter (1). The time range is not identical and the initial amplitudes are not identical either. These values of stability parameter were presented in Table 1. As expected, double distilled water considered as the reference fluid in our study proved to be stable $(s=0)$. The stability parameter is decreasing from $0.00028 \mathrm{~s}^{-1}$ in sample $\mathrm{S} 1$ to $0.00012 \mathrm{~s}^{-1}$ in 
S2. The first period, beginning at the same lapse of time after stirring, increases from 100s (S1) to 800s (S2). This duration proves to be proportional to the suspension concentration. Due to the increasing dispersion and signal attenuation with suspension concentration, the stability parameter (1) is not proportional with the concentration. For the tested suspensions, the stability parameter cannot be considered as the only relevant parameter, but also the duration of the first period is an indicator of stability.

Table 1. Stability parameter for the tested samples.

\begin{tabular}{cccccc}
\hline Sample & $\begin{array}{c}\text { Initial } \\
\text { Amplitude (a.u.) }\end{array}$ & $\begin{array}{c}\text { Initial } \\
\text { Velocity }(\mathbf{m} / \mathbf{s})\end{array}$ & $\begin{array}{c}\text { Final Velocity } \\
(\mathbf{m} / \mathbf{s})\end{array}$ & First Period (s) & \multirow{2}{*}{$(\mathbf{1} / \mathbf{s})$} \\
\hline Double Distilled Water & $3.5 \times 10^{-3}$ & 1486 & 1486 & $\infty$ & $0.00000 \pm 1 \times 10^{-6}$ \\
S1 & $2.2 \times 10^{-3}$ & 1479 & 1479 & 100 & $0.00028 \pm 1 \times 10^{-6}$ \\
S2 & $1.3 \times 10^{-3}$ & 1507 & 1479 & 700 & $0.00012 \pm 1 \times 10^{-6}$ \\
\hline
\end{tabular}

Also, in Table 1 are indicated the measured velocities of the first and last signal for each sample. The final velocities for samples S1 and S2 are similar, proving that the suspension reached almost the same final state, close to the properties of the solvent. However, the initial velocity for S2 was less than the final value. The results obtained in this study by ultrasound-based technique regarding the gels stability revealed that the amplitudes have a linear variation of signal amplitudes in time, during the first stage and velocity of ultrasonic waves is not monotonic with increasing suspension concentration. Furthermore, the duration of the first period is a good indicator of suspension stability. For the analyzed gels, both the stability parameter and the duration of the first period provided relevant information on the stability of the solutions. Compared to the methods proposed in [50-52] which are measuring the quasi-static ultrasonic attenuation, we suggest using a stability parameter which captures the dynamic behavior of the suspension. There is no standard procedure, nor a dedicated device, but an ongoing research with promising results. Establishing the stability of gels obtained by ultrasound-based technique is very important as the dilutions required to use the traditional $\zeta$-potential method can lead to the destruction of aggregates and the modification of the suspension medium [63].

The identification of the phase composition, lattice parameters, and size of crystallites of the Ag:HAp-S1 and Ag:HAp-S2 composite layers obtained by spin-coating technique was accomplished by comparing XRD diffractograms of the samples with standard JCPDS cards of the HAp (9-0432) and $\mathrm{Ag}_{3}(\mathrm{PO})_{4}$ (6-505). The XRD analysis of Ag:HAp-S1 and Ag:HAp-S2 composite layers by Rietveld refinement of $\mathrm{X}$-ray diffraction patterns have clearly identified a single phase of hydroxyapatite. A good fit has been obtained by the Rietveld method using MAUD (Material Analysis Diffraction) [64]. The XRD patterns of the Ag:HAp-S1 and Ag:HAp-S2 composite layers deposited on the pure Ti disks were presented in Figure 5. The XRD patterns of Ag:HAp-S1 and Ag:HAp-S2 composite layers revealed a similar curve and the characteristic diffraction peaks such as (002), (210), (211), (300), (202), (310), (222), (213), and (004) were clearly noticed, indicating the formation of hexagonal HAp (space group $\left.P 6_{3} / m\right)$.

The standard peak of Ag positioned at $37.1^{\circ}$ was not observed in the samples. Furthermore, no other additional phase was observed. The calculated lattice constants of Ag:HAp-S1 ( $a=b=0.9419 \mathrm{~nm}$, $c=0.6882 \mathrm{~nm})$ and Ag:HAp-S2 $(a=b=0.9421 \mathrm{~nm}, c=0.6880 \mathrm{~nm})$ composite layers were achieved from the XRD peaks corresponding to the (002) planes, which are well resolved and appears no interferences. The calculated lattice constants for Ag:HAp-S1 and Ag:HAp-S2 composite layers were in good agreement with that of the standard hexagonal HAp $(a=b=0.9418 \mathrm{~nm}, c=0.6884 \mathrm{~nm}$, space group $P 6_{3} / m$ ). Considering that the diameter of the silver ions is only slightly higher than the diameter of the calcium ion (the ratio of ionic radiation $\mathrm{Ag}^{+} / \mathrm{Ca}^{2+}=1.09$ ), it was expected that remarkable line shifts changes would not be observed at this level of doping. 


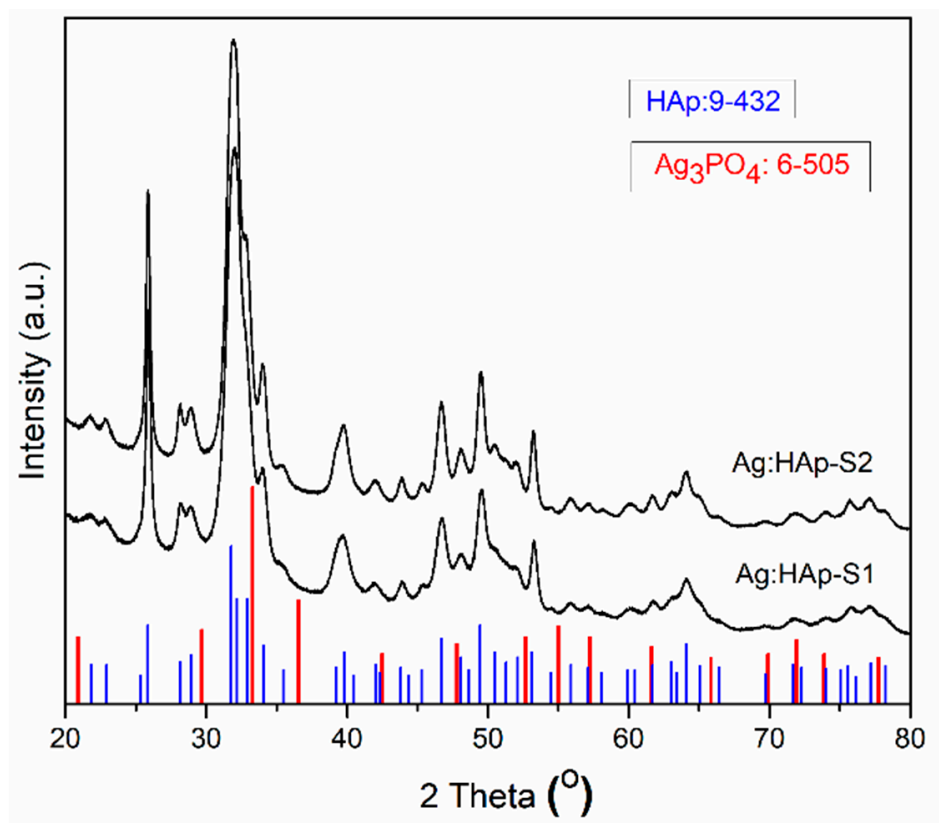

Figure 5. X-ray diffraction (XRD) patterns of Ag:HAp-S1 and Ag:HAp-S2 composite layers obtained by sol-gel dip coating method after the thermal treatment.

SEM micrographs of Ag:HAp-S1 and Ag:HAp-S2 composite layers were shown in Figure 6a,b. The SEM analysis of the Ag:HAp-S1 and Ag:HAp-S2 composite layers deposited onto the pure Ti substrate indicated the formation of ellipsoidal particles that is typical of deposited HAp films by spin-coating technique [65]. The micrographs shown in Figure 6a,b proved that the coating is homogeneous. The composite layers do not show observable cracks. The mean particle size was $16 \pm 3 \mathrm{~nm}$ for the Ag: HAp-S1 sample and $25 \pm 1 \mathrm{~nm}$ for the Ag: HAp-S2 sample. Also, it was observed that the particles are better structured for the Ag: HAp-S2 sample. The particle size was higher for the sample made from the gel initially obtained at $100{ }^{\circ} \mathrm{C}$. In addition, the thickness of the Ag: HAp coatings was $180.2 \mathrm{~nm}$ for Ag: HAp-S1 and $203.5 \mathrm{~nm}$ for Ag: HAp-S2 (Figure 7a,b). However, it can be concluded that both the morphology and the thickness of the layers made by spin-coating technique is sensitive to the initial gel from which the deposition was made. To evaluate the distribution of the constituent elements in the Ag:HAp-S1 and Ag:HAp-S2 composite layers, the elemental mapping was conducted. The uniform distribution of the constituent elements ( $\mathrm{Ag}, \mathrm{Ca}, \mathrm{P}$, and $\mathrm{O}$ ) was observed in both analyzed samples as can be seen Figures 8 and 9. In Table 2 was presented the elemental composition estimated from EDX analysis.

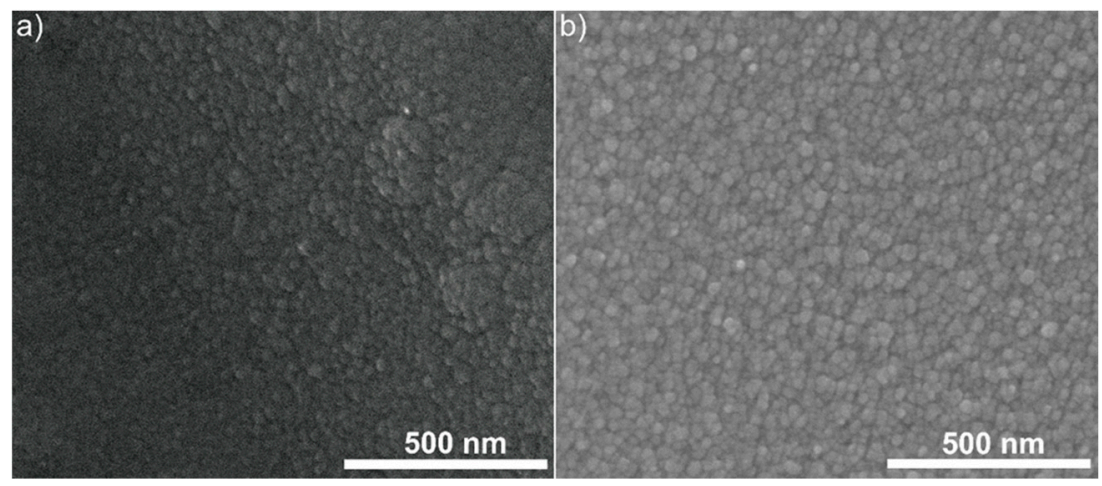

Figure 6. Scanning electron microscopy (SEM) micrographs of Ag:HAp-S1 (a) and Ag:HAp-S2 (b) composite layers. 


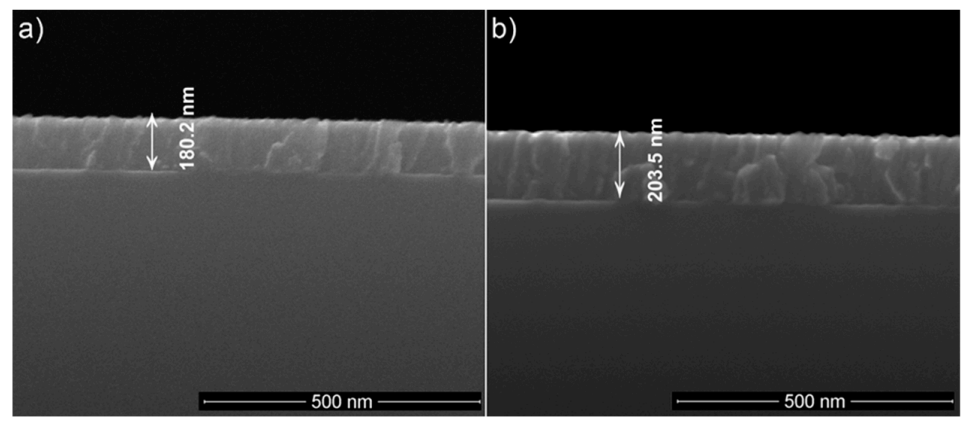

Figure 7. The thickness of the Ag:HAp-S1 (a) and Ag:HAp-S2 (b) composite layers.

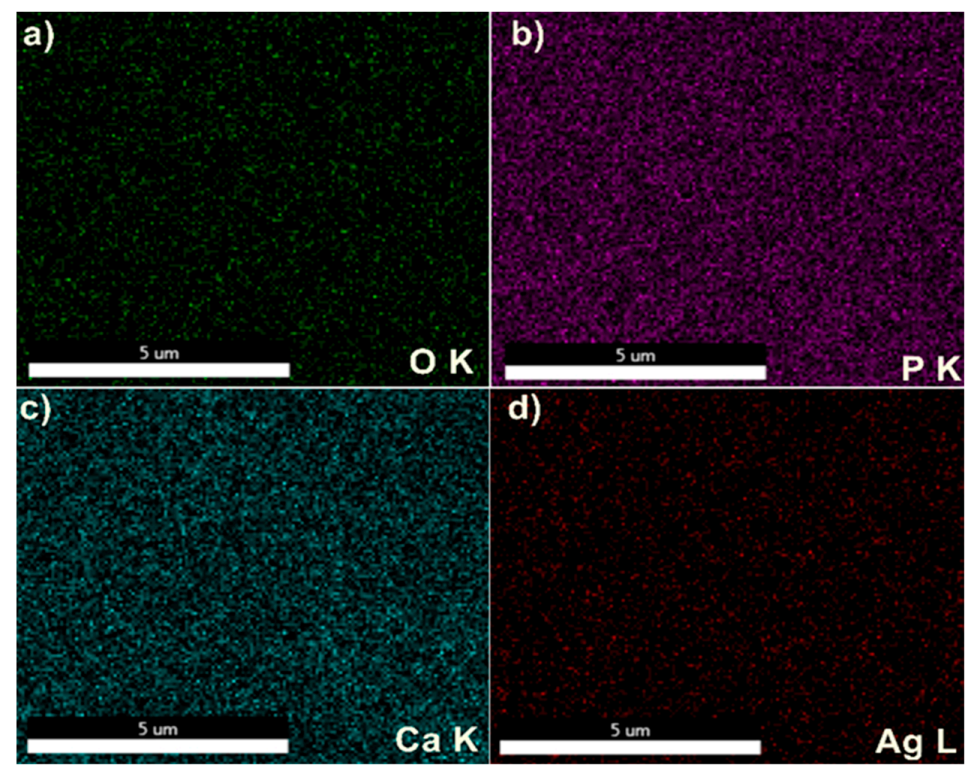

Figure 8. Elemental mapping of the Ag:HAp-S1 composite layers.

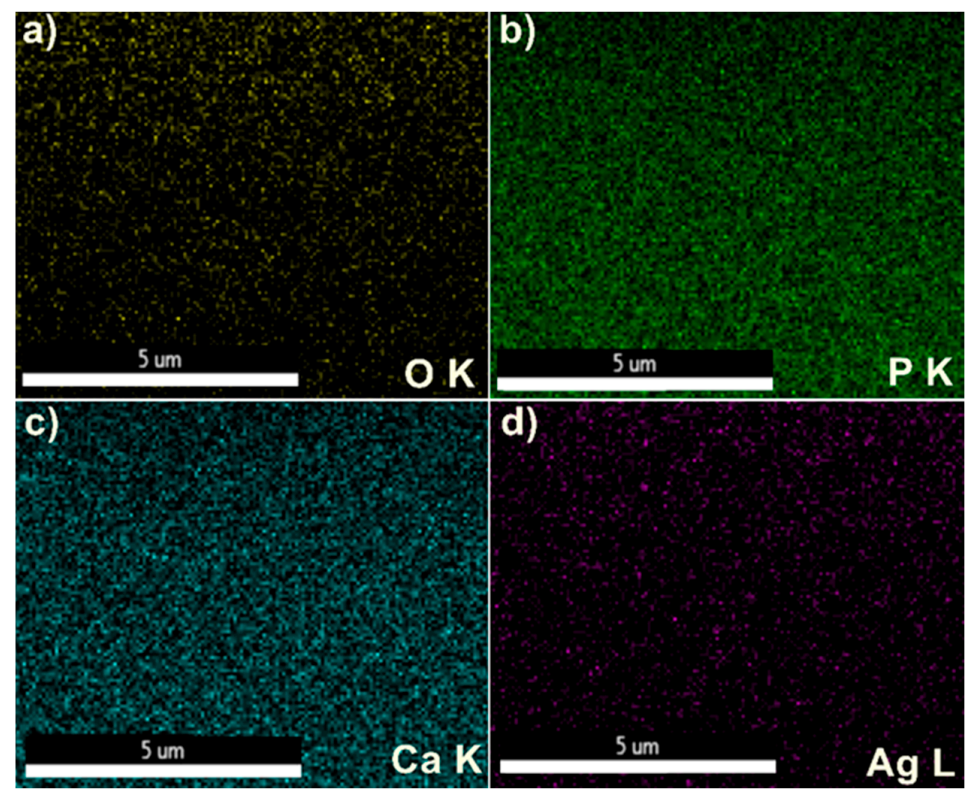

Figure 9. Elemental mapping of the Ag:HAp-S2 composite layers. 
Table 2. The elemental composition estimated from X-ray Energy Dispersive Spectroscopy (EDX) analysis.

\begin{tabular}{ccccc}
\hline \multirow{2}{*}{ Sample } & \multicolumn{4}{c}{ Atomic Composition (\%) } \\
\cline { 2 - 5 } & $\mathbf{C a}$ & $\mathbf{P}$ & $\mathbf{A g}$ & $\mathbf{O}$ \\
\hline Ag:HAp-S1 & 13.68 & 8.24 & 0.08 & 78 \\
Ag:HAp-S2 & 13.65 & 8.23 & 0.1 & 78.02 \\
\hline
\end{tabular}

The atomic ratio of $(\mathrm{Ca}+\mathrm{Ag}) / \mathrm{P}$ was 1.67 for both samples (Ag:HAp-S1 and Ag:HAp-S2). The atomic ratio of $\mathrm{Ca} / \mathrm{P}$ was 1.66 for Ag:HAp-S1 while for Ag:HAp-S2 was 1.658. These values were in good agreement with the standard atomic ratio of $\mathrm{Ca} / \mathrm{P}$ which is 1.67 . However, a slight decrease in the atomic $\mathrm{Ca} / \mathrm{P}$ ratio compared to the standard value can be observed. The value of the atomic ratio decreased as the silver concentration increased in the sample. This slight decrease in the $\mathrm{Ca} / \mathrm{P}$ atomic ratio could be attributed to the substitution of $\mathrm{Ca}^{2+}$ with the $\mathrm{Ag}$ during the preparation process.

The effects of two antifungal agents (Ag:HAp-S1 and Ag:HAp-S2) against C. albicans were evaluated at two different time points, the initial time (T0) and six months after the time at which the layers were made (T6). The antifungal activity of composite layers at T0 (Ag:HAp-S1_T0, Ag:HAp-S2_T0) and T6 (Ag:HAp-S1_T6 and Ag:HAp-S2_T6) was assessed using Candida albicans ATCC 10231 microbial strain.

The results of the antibacterial assays emphasized that Ti discs exhibited no antimicrobial activity against the tested fungal strain. Furthermore, the results indicated that both Ag:HAp-S1 and Ag:HAp-S2 composite layers deposited on Ti substrates presented antifungal activity against Candida albicans ATCC 10231 microbial strain. Figure 10c,f emphasized that Ag:HAp-S2 composite layers exhibited a pronounced antifungal activity compared to Ag:HAp-S1 composite layers against the tested microbial strain. On the other hand, it could be seen that the growth inhibitory zone around the two antifungal agents against $C$. albicans increased as the concentration of antifungal agent increased.

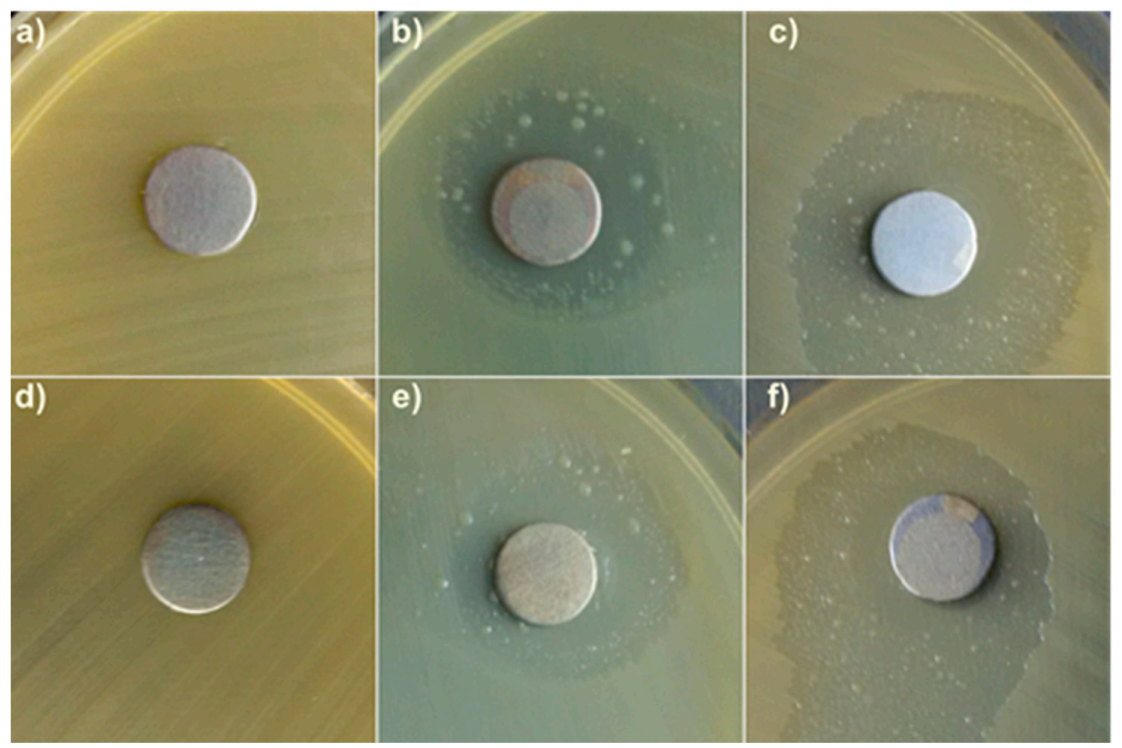

Figure 10. Qualitative assay of the inhibitory activity of Ag:HAp-S1 and Ag:HAp-S2 at time T0 (Ag:HAp-S1_T0 (b) and Ag:HAp-S2_T0 (c)) and T6 (Ag:HAp-S1_T6 (e) and Ag:HAp-S2_T6 (f)) composite layers against Candida albicans ATCC 10231 microbial strain; Ti discs were used as control (a,d).

In Figure 10b-f it can be seen that both composite layers (Ag: HAp-S1 and Ag:HAp-S2) had a strong inhibitory effect on Candida albicans microbial strain ATCC 10231 at time T0 (Ag:HAp-S1_T0 and Ag:HAp-S2_T0) and T6 (Ag: HAp-S1_T6 and Ag: HAp-S2_T6). Due to the fact that Ti discs presented no inhibitory effect on the growth of the tested microbial strain, the antifungal activity of 
the Ag:HAp-S1 and Ag:HAp-S2 composite layers at time T0 (Ag:HAp-S1_T0, Ag:HAp-S2_T0) and T6 (Ag:HAp-S1_T6 and Ag:HAp-S2_T6) was attributed to the silver ions present in the Ag:HAp layers. These findings are in good agreement with previously reported studies regarding the antifungal activity of Ag:HAp composite layers [66,67]. The antifungal activity of composite layers at time T0 (Ag:HAp-S1_T0 and Ag:HAp-S2_T0) and T6 (Ag:HAp-S1_T6 and Ag:HAp-S2_T6) against Candida albicans ATCC 10231 microbial strain was also confirmed by measuring the inhibition zone diameters (Figure 11). The results of the qualitative microbial assays are presented in Figure 10 and the inhibition zone diameters measured in $\mathrm{mm}$ are illustrated in Figure 11.

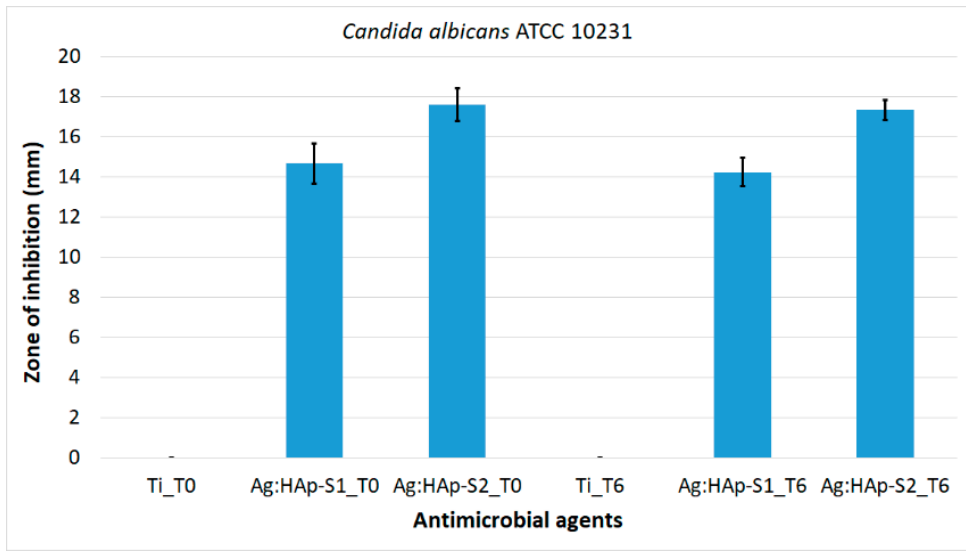

Figure 11. Inhibition zone diameters of Ag:HAp-S1_T0, Ag:HAp-S2_T0, Ag:HAp-S1_T6 and Ag:HAp-S2_T6 composite layers against Candida albicans ATCC 10231 fungal strain.

The size of the clearance area measured at time $\mathrm{T} 0$ and $\mathrm{T} 6$ ranged from zero for Ti samples to $17.61 \pm 0.8 \mathrm{~mm}$ for the Ag:HAp-S2 sample at time T0 (Ag:HAp-S2_T0). The size of the clearance zone measured at time T6 was equal to $17.34 \pm 0.5 \mathrm{~mm}$. Moreover, the size of the clearance area measured at the two time intervals (T0 and T6) varied insignificantly for the two analyzed samples (Ag:HAp-S1 and Ag:HAp-S2) indicating that the antifungal activity of the composite layers is constant over time. The results highlighted that the Ag:HAp-S2 composite layers presented a greater antifungal activity against the tested microbial strain comparative to Ag:HAp-S1 samples.

The effects of the Ag:HAp-S1 and Ag:HAp-S2 composite layers on the morphology of C. albicans at time T0 (Ag:HAp-S1_T0 and Ag:HAp-S2_T0) and T6 (Ag:HAp-S1_T6 and Ag:HAp-S2_T6) were investigated by two scanning microscopy techniques, namely SEM and CLSM. The images of C. albicans cell development on the surfaces of Ti substrate and Ag:HAp-S1 and Ag:HAp-S2 composite layers at time T0 (Ti_T0, Ag:HAp-S1_T0 and Ag:HAp-S2_T0) and T6 (Ti_T6, Ag:HAp-S1_T6 and Ag:HAp-S2_T6) resulting from SEM observations were presented in Figure 12a-f.

The SEM observation showed that the morphology of the fungal cells was typical to the $C$. albicans fungal strain, with round and oval shapes. The C. albicans fungal cells were in the order of microns in size. Moreover, the SEM analysis revealed that the fungal cells adhered and developed biofilms on the Ti discs after $24 \mathrm{~h}$ of incubation. SEM observations have highlighted the inhibitory effects of the Ag:HAp-S1 and Ag:HAp-S2 composite layers at time T0 and T6 against $C$. albicans fungal strain. The SEM images show that the Ag:HAp-S1 and Ag:HAp-S2 composites layers have strong inhibitory effects against $C$. albicans cells development at the two time intervals. In addition, based on SEM images, no changes were observed regarding the development of C. albicans cells at time T6 (Figure 12e,f) versus T0 (Figure 12b,c), suggesting that the layers preserved the antifungal effect against the C. albicans strain.

The development and adhesion of $C$. albicans cells on the surface of the Ti discs and Ag:HAp-S1 and Ag:HAp-S2 composite layers at the two time intervals T0 and T6 after $24 \mathrm{~h}$ of incubation was examined by CLSM. The images acquired using CLSM proved much more clearly, than those acquired through the SEM, that no changes were observed regarding the C. albicans cells development on 
Ag:HAp-S1 and Ag:HAp-S2 composite layers at the two time intervals T0 and T6. CLSM is more useful that SEM for imaging, qualitative analysis, and quantification of various cells [68]. CLSM is an optical imaging technique, with increased optical resolution and contrast of a micrograph, by means of a spatial pinhole which blocks out-of-focus light in image formation [69]. Figure 13 shows the CLSM images of $C$. albicans cell growth on different surfaces. For CLSM visualization, propidium iodide was used as marker to label the fungal cells. The CLSM image of C. albicans cells revealed that the fungal cells stained in red by the propidium iodide developed very well and formed biofilms on the Ti substrate at the two time intervals T0 and T6 after $24 \mathrm{~h}$ of incubation (Figure 13a,d).

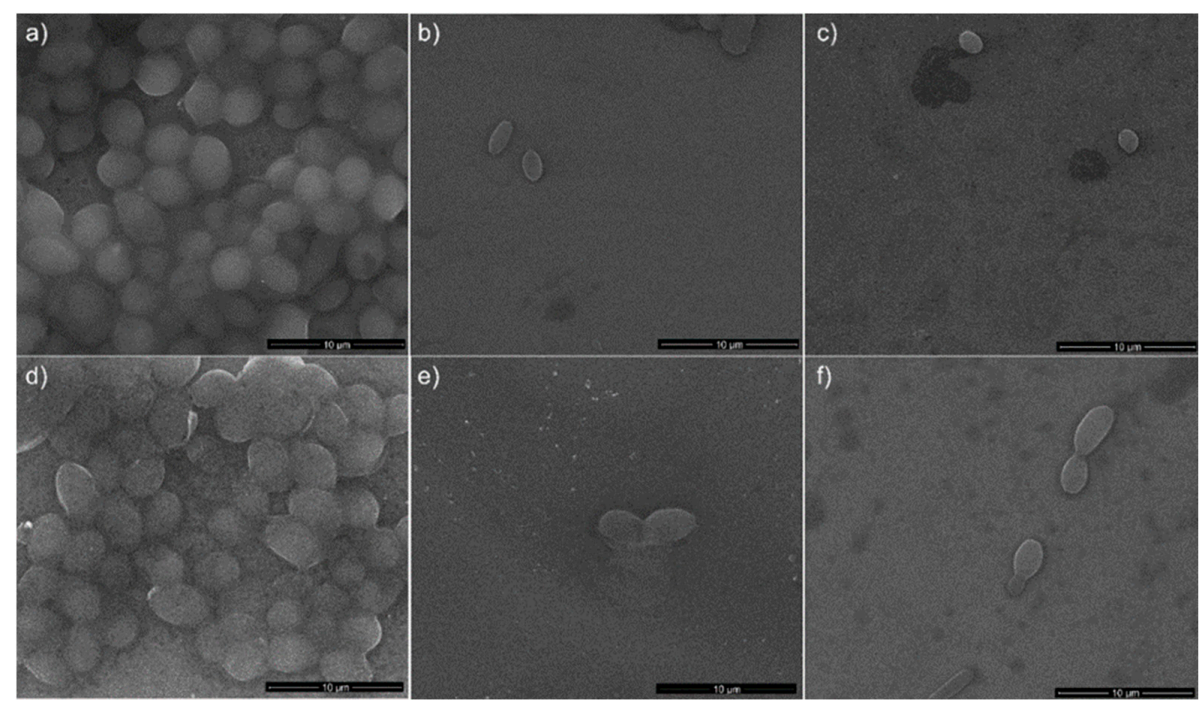

Figure 12. SEM images of Candida albicans ATCC 10231 cell development on Ti discs used as control (a,d) and Ag: HAp-S1 and Ag: HAp-S2 composite layers at the two time intervals T0 (Ag:HAp-S1_T0 (b) and Ag:HAp-S2_T0 (c)) and T6 (Ag:HAp-S1_T6 (e) and Ag:HAp-S2_T6 (f)) after 24 h of incubation.

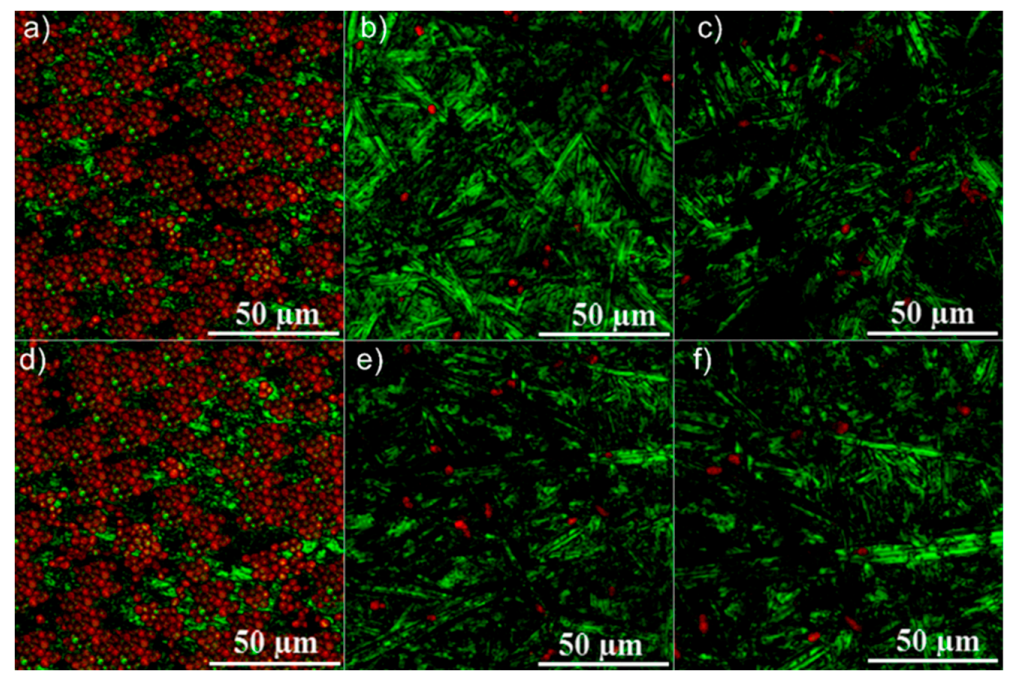

Figure 13. CLSM images of C. albicans ATCC 10231 cell development on Ti discs used as control (a,d) and Ag: HAp-S1 and Ag: HAp-S2 composite layers at the two time intervals T0 (Ag:HAp-S1_T0 (b) and Ag:HAp-S2_T0 (c)) and T6 (Ag:HAp-S1_T6 (e) and Ag:HAp-S2_T6 (f)) after 24 h of incubation.

For a better understanding of the biological activity of the Ag:HAp-S1 and Ag:HAp-S2 composite layers, a cytotoxicity assay test using primary human osteoblast cells obtained from the upper part of patient's femur have been performed. The results of the cytotoxicity assay are presented in Figure 14 . 
The images shown in Figure 14 showed that the Ag: HAp-S1 and Ag: HAp-S2 composite layers analyzed at the two time intervals (T0 and T6) showed no toxic effect against the osteoblast cells. The fluorescence micrographs revealed that the morphology of the cells suffered no significant changes.
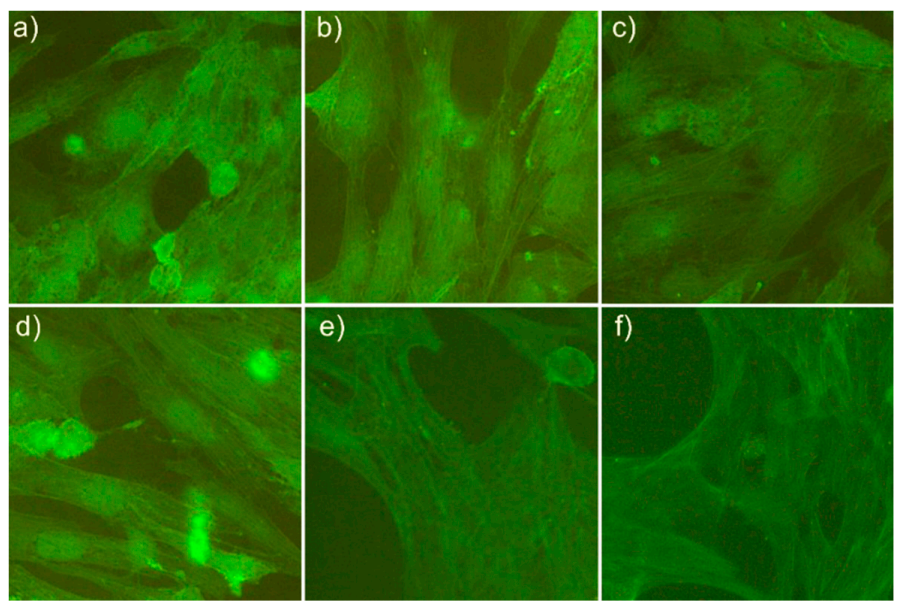

Figure 14. Fluorescence micrographs of osteoblasts cells plated on Ti discs used as control (a,d) and Ag: HAp-S1 and Ag: HAp-S2 composite layers at the two time intervals T0 (Ag:HAp-S1_T0 (b) and Ag:HAp-S2_T0 (c)) and T6 (Ag:HAp-S1_T6 (e) and Ag:HAp-S2_T6 (f)) after $24 \mathrm{~h}$ of incubation.

This study demonstrated that bioceramic layers of Ag:HAp-S1 and Ag:HAp-S2 can induce proliferation of osteoblasts. The presence of silver in HAp-based ceramic gels from which composite layers have been made may induce changes in surface properties that may conduct to the regulation of several cellular functions such as attachment and cell proliferation. Furthermore, it has been observed that the stability of the gels from which the composite layers have been made plays an important role contributing to a better proliferation of osteoblast cells. For the Ag: HAp-S2 sample, a better proliferation of osteoblast cells was observed at the two time intervals analyzed (Figure 14c,f).

It has been observed that the $C$. albicans cells were intact with round morphology presenting a smooth surface after the two time intervals $\mathrm{T} 0$ and $\mathrm{T} 6$ and after $24 \mathrm{~h}$ of incubation on the surface of the Ti disks used as the substrate (Figure 13a,d). Furthermore, the CLSM examination confirmed the results obtained by the qualitative antimicrobial assay and was in good agreement with the SEM analysis. CLSM images highlighted that Ag:HAp-S1 and Ag:HAp-S2 composite layers at the two time intervals T0 (Ag:HAp-S1_T0 and Ag:HAp-S2_T0) and T6 (Ag:HAp-S1_T6 and Ag:HAp-S2_T6) after $24 \mathrm{~h}$ of incubation exhibited a strong antifungal activity against Candida albicans ATCC 10231 and completely inhibited the biofilm formation. The results of the antifungal activity of Ag:HAp-S1 and Ag:HAp-S2 composite layers revealed that the Ag:HAp composite layers have great potential to be used in medical application as antifungal coatings for medical devices. Even more, the results presented in this study emphasized that the Ag:HAp-S1 and Ag:HAp-S2 composite layers kept their biological activity even after 6 months since obtention. Furthermore, the CLSM examination confirmed the results obtained by the qualitative antimicrobial assay was in good agreement with the SEM analysis. CLSM images highlighted that Ag:HAp-S1 and Ag:HAp-S2 composite layers at the two time intervals T0 (Ag:HAp-S1_T0, Ag:HAp-S2_T0) and T6 (Ag:HAp-S1_T6 Ag:HAp-S2_T6) after 24 h of incubation exhibited a strong antifungal activity against Candida albicans ATCC 10231 and completely inhibited the biofilm formation. The results of the antifungal activity of Ag:HAp-S1 and Ag:HAp-S2 composite layers revealed that the Ag:HAp composite layers have great potential to be used in medical applications as antifungal coatings for medical devices. Moreover, the results presented in this study emphasized that the Ag:HAp-S1 and Ag:HAp-S2 composite layers kept their biological activity even after 6 months after they were obtained. 
This work enrolls in the current tendency of nanotechnology, to create new facilities for the medical industry, by developing new materials with multiple applications. The antimicrobial properties of silver have been known for a very long time, with silver ions being incorporated into various medical or health products such as wound dressings or toothpaste. Previous studies have shown that silver-based products could be a new generation of antimicrobial agents [70]. Recently, studies on ceramic/metal biocidal nanocomposites for bone-related applications [71] and antifungal applications of silver-decorated hydroxyapatite nanoparticles [72] have shown that silver nanoparticles can attach to the cell membrane causing structural changes and ultimately cell death [72]. Studies regarding the mechanism responsible for the antimicrobial effects of silver have been addressed in recent studies and it has been reported that silver at nanoscale interacts with microorganism to produce an antimicrobial effect with the membrane of the microbial cells, the cell wall [25,26], DNA [27], and microbial proteins [26]. Furthermore, besides the mechanism identified at the level of the microorganism cell components, it has been reported that silver at a nanoscale level produces reactive oxygen species (ROS) [28]. Possible mechanism for ROS generating by silver ions were presented by Matsumura et al. [29], and Holt and Bard [30] in their studies. They have reported that the impairment of enzymes from the respiratory chain by silver ions may increase ROS generation and that the presence of silver ions in the cells might have a catalytic effect on the generation of ROS inside the cell. Therefore, the level of intracellular ROS accumulation increases due to the presence of silver ions, which initiates mitochondrial fragmentation [31]. Regardless of existing studies, the molecular mechanisms involved in the antimicrobial effects of silver ions remains somewhat controversial. Therefore, incorporating an antifungal agent such as silver into the hydroxyapatite structure could be an important step towards making new materials with antifungal properties.

The current study was designed to evaluate the application of silver-doped hydroxyapatite layers (Ag:HAp-S1 and Ag:HAp-S2) as an antimicrobial agent to cover various materials used in orthopedic and/or dental implants. These layers are expected to help improve the quality of implants and reduce postoperative infections. Moreover, the present study has shown information on the influence of the stability of the solutions used to achieve the composite layers. Ultrasound measurements have allowed us to evaluate the stability of solutions based on variation of the ultrasonic amplitude in time. The results obtained by an ultrasound-based technique, determined the stability of gels used for coatings and have shown that the sol-gel method allows for obtaining stable gels. Better stability was noted for aged gels for $72 \mathrm{~h}$ at $100{ }^{\circ} \mathrm{C}$. Stability of solutions has contributed positively to obtaining more homogeneous layers. The thickness of the composite layers were also influenced by the gels stability. The thickness of the Ag:HAp coatings was $180.2 \mathrm{~nm}$ for Ag:HAp-S1 and $203.5 \mathrm{~nm}$ for Ag:HAp-S2. In addition, layers obtained from the more stable solution (S2) showed better antifungal activity.

In conclusion, we can say that the incorporation of silver ions in the hydroxyapatite gels has allowed the obtaining of bioceramic layers with stable antifungal properties over time. The biological response of these composite layers was evidenced by the development of osteoblast cells and the preservation of their morphology at the two time intervals studied. An absolute novelty consisted in the use of a non-destructive investigation technique for the study of Ag:HAp gels stability using ultrasounds in dynamic regime.

Therefore, we can say that the studies presented in this paper show that the Ag:HAp-S1 and Ag:HAp-S2 composite layers had a good biocompatibility and antifungal properties which recommend them for use in different fields of medicine as it could prevent post-operative infections that may occur due to direct microbial contamination during medical interventions.

\section{Conclusions}

The Ag:HAp composite layers were prepared from stable gels by the spin-coating technique. This method has the advantage of allowing new materials to be made at low cost in a simple and efficient way. In order to evaluate the stability of gels obtained by the sol-gel method, an ultrasound-based technique was used, which is a dynamic non-destructive method and has the advantage that it can be 
applied to undiluted opaque solutions. Thus, we prepared by the sol-gel method two Ag:HAp gels that we used to deposit coatings on pure Ti by spin-coating technique. The XRD analyses revealed the characteristic diffraction peaks of hexagonal HAp (space group $P 6_{3} / m$ ) in both Ag:HAp-S1 and Ag:HAp-S2 coatings. It has been found that the fungicidal effect of Ag:HAp composite layers is higher in the case of layers obtained from the more stable suspension. The results revealed by the antifungal assay have highlighted that both Ag:HAp-S1 and Ag:HAp-S2 coatings exhibited antifungal properties against Candida albicans ATCC 10231. Moreover, it has been remarked that the C. albicans cells were intact with round morphology, presenting a smooth surface after the two time intervals T0 and T6 and after $24 \mathrm{~h}$ of incubation on the surface of the Ti disks used as the substrate. This study demonstrated that bioceramic layers of Ag:HAp-S1 and Ag:HAp-S2 can induce proliferation of osteoblasts. The cells retained their typical osteoblastic morphology at the two time intervals at which the cytotoxicity test was performed. The results suggested that the coatings have maintained their biological and antifungal properties in time, the results of the antimicrobial investigations of the Ag:HAp samples were similar when tested after six months.

These results attested that Ag:HAp coatings could be successfully used in medical applications as biocompatible and antifungal coatings for medical devices.

Author Contributions: Conceptualization, D.P. and M.V.P; Methodology, D.P.; Software, M.V.P; Validation, D.P., S.L.I., and M.V.P; Formal Analysis, D.P., S.L.I., and M.V.P; Investigation, D.P., S.L.I., and M.V.P; Resources, D.P., S.L.I., and M.V.P; Data Curation, D.P., S.L.I., and M.V.P; Writing-Original Draft Preparation, D.P., S.L.I., and M.V.P; Writing-Review \& Editing, D.P., S.L.I., and M.V.P; Visualization, D.P., S.L.I., and M.V.P; Supervision, M.V.P; Project Administration, D.P.; Funding Acquisition, D.P.

Funding: This research was (partially) supported by a grant of the Romanian Ministry of Research and Innovation (PCCDI-UEFISCDI, project number PN-III-P1-1.2-PCCDI-2017-0062/contract no. 58/component project no. 2), Internal Contract No. T-IS 251801/04.05.2018 and Core Program funded by Romanian Ministry of Research and Innovation (PN18-110101).

Acknowledgments: We thank A. Richard and A. Sauldubois from the "Centre de Microscopie Electronique" of University of Orléans for assistance in SEM data acquisition.

Conflicts of Interest: The authors declare no conflict of interest.

\section{References}

1. Aslam, S.; Darouiche, R.O. Antimicrobial therapy for bone and joint infections. Curr. Infect. Dis. Rep. 2008, 11, 7-13. [CrossRef]

2. Trampuz, A.; Widmer, A.F. Infections associated with orthopedic implants. Curr. Opin. Infect. Dis. 2006, 19, 349-356. [CrossRef] [PubMed]

3. Kucharıkova, S.; Gerits, E.; De Brucker, K.; Braem, A.; Ceh, K.; Majdic, G.; Spanic, T.; Pogorevc, E.; Verstraeten, N.; Tournu, H.; et al. Covalent immobilization of antimicrobial agents on titanium prevents Staphylococcus aureus and Candida albicans colonization and biofilm formation. J. Antimicrob. Chemother. 2016, 71, 936-945. [CrossRef] [PubMed]

4. Von Eiff, C.; Jansen, B.; Kohnen, W. Infections associated with medical devices: Pathogenesis, management and prophylaxis. Drugs 2005, 65, 179-214. [CrossRef] [PubMed]

5. Darouiche, R.O. Treatment of infections associated with surgical implants. N. Engl. J. Med. 2004, 350, 1422-1429. [CrossRef] [PubMed]

6. Gerits, E.; Kucharıkova, S.; Van Dijck, P.; Erdtmann, M.; Krona, A.; Lovenklev, M.; Frohlich, M.; Dovgan, B.; Impellizzeri, F.; Braem, A.; et al. Antibacterial activity of a new broad-spectrum antibiotic covalently bound to titanium surfaces. J. Orthop. Res. 2016, 34, 2191-2198. [CrossRef] [PubMed]

7. De Avila, E.D.; De Molon, R.S.; Lima, B.P.; Lux, R.; Shi, W.; Jafelicci, M., Jr.; Spolidorio, D.M.; Vergani, C.E.; Mollo, F., Jr. The impact of physical chemical characteristics of implant abutment surfaces on bacteria adhesion. J. Oral. Implantol. 2016, 42, 153-158. [CrossRef] [PubMed]

8. Chu, V.H.; Crosslin, D.R.; Friedman, J.Y.; Reed, S.D.; Cabell, C.H.; Griffiths, R.I.; Masselink, L.E.; Kaye, K.S.; Corey, G.R.; Reller, L.B.; et al. Staphylococcus aureus bacteremia in patients with prosthetic devices: Costs and outcomes. Am. J. Med. 2005, 118, 1416.e19-1416.e24. [CrossRef] [PubMed] 
9. Cataldo, M.A.; Petrosillo, N.; Cipriani, M.; Cauda, R.; Tacconelli, E. Prosthetic joint infection: Recent developments in diagnosis and management. J. Infect. 2010, 61, 443-448. [CrossRef] [PubMed]

10. Stan, G.E. Bioreactivity evaluation in simulated body fluid of magnetron sputtered glass and glass-ceramic coatings: A FTIR spectroscopy study. Dig. J. Nanomater. Biostruct. 2010, 5, 557-566.

11. Jankovic, A.; Erakovic, S.; Ristoscu, C.; Mihailescu, N.; Duta, L.; Visan, A.; Stan, G.E.; Popa, A.C.; Husanu, M.A.; Luculescu, C.R.; et al. Structural and biological evaluation of lignin addition to simple and silver-doped hydroxyapatite thin films synthesized by matrix-assisted pulsed laser evaporation. J. Mater. Sci. Mater. Med. 2015, 26, 17. [CrossRef] [PubMed]

12. Predoi, D.; Iconaru, S.L.; Deniaud, A.; Chevallet, M.; Michaud-Soret, I.; Buton, N.; Prodan, A.M. Textural, Structural and Biological Evaluation of Hydroxyapatite Doped with Zinc at Low Concentrations. Materials 2017, 10, 229. [CrossRef] [PubMed]

13. Chen, W.; Oh, S.; Ong, A.P.; Oh, N.; Liu, Y.; Courtney, H.S.; Appleford, M.; Ong, J.L. Antibacterial and osteogenic properties of silver-containing hydroxyapatite coatings produced using a sol gel process. J. Biomed. Mater. Res. A. 2007, 15, 899-906. [CrossRef] [PubMed]

14. Groza, A.; Ciobanu, C.S.; Popa, L.C.; Iconaru, S.L.; Chapon, P.; Luculescu, C.; Ganciu, M.; Predoi, D. Structural Properties and Antifungal Activity against Candida albicans Biofilm of Different Composite Layers Based on $\mathrm{Ag} / \mathrm{Zn}$ Doped Hydroxyapatite-Polydimethylsiloxanes. Polymers 2016, 8, 131. [CrossRef]

15. Costescu, A.; Ciobanu, C.S.; Iconaru, S.L.; Ghita, R.V.; Chifiriuc, M.C.; Marutescu, L.G.; Predoi, D. Fabrication, characterization, and antimicrobial activity, evaluation of low silver concentrations in silver-doped hydroxyapatite nanoparticles. J. Nanomater. 2013, 2013, 1-9. [CrossRef]

16. Fielding, G.A.; Roy, M.; Bandyopadhyay, A.; Bose, S. Antibacterial and biological characteristics of silver containing and strontium doped plasma sprayed hydroxyapatite coatings. Acta Biomater. 2012, 8, 3144-3152. [CrossRef] [PubMed]

17. Klasen, H.J. A historical review of the use of silver in the treatment of burns. II. Renewed interest for silver. Burns 2000, 26, 131-138. [CrossRef]

18. Dibrov, P.; Dzioba, J.; Gosink, K.K.; Hase, C.C. Chemiosmotic mechanism of antimicrobial activity of $\mathrm{Ag}^{+}$in Vibrio cholera. Antimicrob. Agents Chemother. 2002, 46, 2668-2670. [CrossRef] [PubMed]

19. Spadaro, J.A.; Berger, T.J.; Barranco, S.D.; Chapin, S.E.; Becker, R.O. Antibacterial effects of silver electrodes with weak direct current. Antimicrob. Agents Chemother. 1974, 6, 637-642. [CrossRef] [PubMed]

20. Sondi, I.; Salopek-Sondi, B. Silver nanoparticles as antimicrobial agent: A case study on E. coli as a model for Gram-negative bacteria. J. Colloid. Interface Sci. 2004, 275, 177-182. [CrossRef] [PubMed]

21. Hwang, I.S.; Lee, J.; Hwang, J.H.; Kim, K.J.; Lee, D.G. Silver nanoparticles induce apoptotic cell death in Candida albicans through the increase of hydroxyl radicals. Febs J. 2012, 279, 1327-1338. [CrossRef] [PubMed]

22. Slawson, R.M.; Van Dyke, M.I.; Lee, H.; Trevors, J.T. Germanium and silver resistance, accumulation, and toxicity in microorganisms. Plasmid 1992, 27, 72-79. [CrossRef]

23. Kim, K.J.; Sung, W.S.; Suh, B.K.; Moon, S.K.; Choi, J.S.; Kim, J.G.; Lee, D.G. Antifungal activity and mode of action of silver nano-particles on Candida albicans. Biometals 2009, 22, 235-242. [CrossRef] [PubMed]

24. Yamanaka, M.; Hara, K.; Kudo, J. Bactericidal actions of a silver ion solution on Escherichia coli, studied by energy-filtering transmission electron microscopy and proteomic analysis. Appl. Environ. Microbiol. 2005, 71, 7589-7593. [CrossRef] [PubMed]

25. Yang, W.; Shen, C.; Ji, Q.; An, H.; Wang, J.; Liu, Q.; Zhang, Z. Food storage material silver nanoparticles interfere with DNA replication fidelity and bind with DNA. Nanotechnology 2009, 20, 085102. [CrossRef] [PubMed]

26. Park, H.J.; Kim, J.Y.; Lee, J.H.; Hahn, J.S.; Gu, M.B.; Yoon, J. Silver-ion-mediated reactive oxygen species generation affecting bactericidal activity. Water Res. 2009, 43, 1027-1032. [CrossRef] [PubMed]

27. Matsumura, Y.; Yoshikata, K.; Kunisaki, S.; Tsuchido, T. Mode of bactericidal action of silver zeolite and its comparison with that of silver nitrate. Appl. Environ. Microbiol. 2003, 69, 4278-4281. [CrossRef] [PubMed]

28. Holt, K.B.; Bard, A.J. Interaction of silver(I) ions with the respiratory chain of Escherichia coli: An electrochemical and scanning electrochemical microscopy study of the antimicrobial mechanism of micromolar $\mathrm{Ag}^{+}$. Biochemistry 2005, 44, 13214-13223. [CrossRef] [PubMed]

29. Pozniakovsky, A.I.; Knorre, D.A.; Markova, O.V.; Hyman, A.A.; Skulachev, V.P.; Severin, F.F. Role of mitochondria in the pheromone- and amiodarone-induced programmed death of yeast. J. Cell. Biol. 2005, 168, 257-269. [CrossRef] [PubMed] 
30. Kohanski, M.A.; Dwyer, D.J.; Hayete, B.; Lawrence, C.A.; Collins, J.J. A common mechanism of cellular death induced by bactericidal antibiotics. Cell 2007, 130, 797-810. [CrossRef] [PubMed]

31. Franci, G.; Falanga, A.; Galdiero, S.; Palomba, L.; Rai, M.; Morelli, G.; Galdiero, M. Silver nanoparticles as potential antibacterial agents. Molecules 2015, 20, 8856-8874. [CrossRef] [PubMed]

32. Silver, S. Bacterial silver resistance: Molecular biology and uses and misuses of silver compounds. FEMS Microbiol. Rev. 2003, 27, 341-353. [CrossRef]

33. Lu, H.; Liu, Y.; Guo, J.; Wu, H.; Wang, J.; Wu, G. Biomaterials with antibacterial and osteoinductive properties to repair infected bone defects. Int. J. Mol. Sci. 2016, 17, 334. [CrossRef] [PubMed]

34. Kim, T.H.; Kim, M.; Park, H.S.; Shin, U.S.; Gong, M.S.; Kim, H.W. Size-dependent cellular toxicity of silver nanoparticles. J. Biomed. Mater. Res. Part A 2012, 100, 1033-1043. [CrossRef] [PubMed]

35. Hussain, S.M.; Hess, K.L.; Gearhart, J.M.; Geiss, K.T.; Schlager, J.J. In vitro toxicity of nanoparticles in BRL 3A rat liver cells. Toxicol. In Vitro 2005, 19, 975-983. [CrossRef] [PubMed]

36. Qin, H.; Zhu, C.; An, Z.; Jiang, Y.; Zhao, Y.; Wang, J.; Liu, X.; Hui, B.; Zhang, X.; Wang, Y. Silver nanoparticles promote osteogenic differentiation of human urine-derived stemcells at noncytotoxic concentrations. Int. J. Nanomed. 2014, 9, 2469-2478. [CrossRef] [PubMed]

37. Mahmood, M.; Li, Z.; Casciano, D.; Khodakovskaya, M.V.; Chen, T.; Karmakar, A.; Dervishi, E.; Xu, Y.; Mustafa, T.; Watanabe, F. Nanostructural materials increase mineralization in bone cells and affect gene expression through miRNA regulation. J. Cell. Mol. Med. 2011, 15, 2297-2306. [CrossRef] [PubMed]

38. Iconaru, S.L.; Chapon, P.; Le Coustumer, P.; Predoi, D. Antimicrobial activity of thin solid films of silver doped hydroxyapatite prepared by sol-gel method. Sci. World J. 2014, 2014, 165351. [CrossRef] [PubMed]

39. Erakovic, S.; Jankovic, A.; Ristoscu, C.; Duta, L.; Serban, N.; Visan, A.; Mihailescu, I.N.; Stan, G.E.; Socol, M.; Iordache, O.; et al. Antifungal activity of Ag:hydroxyapatite thin films synthesized by pulsed laser deposition on $\mathrm{Ti}$ and $\mathrm{Ti}$ modified by $\mathrm{TiO}_{2}$ nanotubes substrates. Appl. Surf. Sci. 2014, 293, 37-45. [CrossRef]

40. Kojic, E.M.; Darouiche, R.O. Candida infections of medical devices. Clin. Microbiol. Rev. 2004, 17, $255-267$. [CrossRef] [PubMed]

41. Chandra, J.; Guangyin, Z.; Ghannoum, M.A. Fungal biofilms and antimycotics. Curr. Drug Targets 2005, 6, 887-894. [CrossRef] [PubMed]

42. Høiby, N.; Bjarnsholt, T.; Moser, C.; Bassi, G.L.; Coenye, T.; Donelli, G.; Hall-Stoodley, L.; Holá, V.; Imbert, C.; Kirketerp-Møller, K.; et al. ESCMID guideline for the diagnosis and treatment of biofilm infections 2014. Clin. Microbiol. Infect. 2015, 21, S1-S25. [CrossRef] [PubMed]

43. Chandra, J.; Mukherjee, P.K.; Ghannoum, M.A. In vitro growth and analysis of Candida biofilms. Nat. Protoc. 2008, 3, 1909-1924. [CrossRef] [PubMed]

44. Kraneveld, E.A. Molecular Characterization of Candida in the Oral Cavity and Factors Involved in Biofilm Formation and Virulence; University of Amsterdam: Amsterdam, The Netherlands, 2014.

45. Chandra, J.; Mukherjee, P.K.; Ghannoum, M.A. Candida biofilms associated with CVC and medical devices. Mycoses. 2011, 55, 46-57. [CrossRef]

46. Peleg, A.Y.; Hogan, D.A.; Mylonakis, E. Medically important bacterial-fungal interactions. Nat. Rev. Microbiol. 2010, 8, 340-349. [CrossRef] [PubMed]

47. Williams, D.W.; Jordan, R.P.; Wei, X.Q.; Alves, C.T.; Wise, M.P.; Wilson, M.J.; Lewis, M.A. Interactions of Candida albicans with host epithelial surfaces. J. Oral. Microbiol. 2013, 5, 22434. [CrossRef] [PubMed]

48. Povey, M.J.W. Ultrasonic Techniques for Fluids Characterization; Academic Press: San Diego, CA, USA, 1997.

49. Dukhin, A.S.; Goetz, P.J. Ultrasound for Characterizing Colloids, Particle Sizing, Zeta Potential, Rheology; Elsevier: San Diego, CA, USA, 2002.

50. Povey, M.J.W. Ultrasound particle sizing: A review. Particuology 2013, 11, 135-147. [CrossRef]

51. Stoch, A.; Jastrzebski, W.; Długon, E.; Lejda, W.; Trybalska, B.; Stoch, G.J.; Adamczyk, A. Sol-gel derived hydroxyapatite coatings on titanium and its alloy Ti6Al4V. J. Mol. Struct. 2005, 744, 633-640. [CrossRef]

52. Zreiqata, H.; Valenzuelab, S.M.; Nissanc, B.B.; Roestc, R.; Knabed, C.; Radlanskid, R.J.; Renzd, H.; Evanse, P.J. The effect of surface chemistry modification of titanium alloy on signalling pathways in human osteoblasts. Biomaterials 2005, 26, 7579-7586. [CrossRef] [PubMed]

53. Gopi, D.; Karthika, A.; Nithiya, S.; Kavitha, L. In vitro biological performance of minerals substituted hydroxyapatite coating by pulsed electrodeposition method. Mater. Chem. Phys. 2014, 144, 75-85. [CrossRef] 
54. Himratul-Aznita, W.H.; Mohd-Al-Faisal, N.; Fathilah, A.R. Determination of the percentage inhibition of diameter growth (PIDG) of Piper betle crude aqueous extract against oral Candida species. J. Med. Plants Res. 2011, 5, 878-884.

55. Cavalcanti, Y.W.; Wilson, M.; Lewis, M.; Del-Bel-Cury, A.A.; da Silva, W.J.; Williams, D.W. Modulation of Candida albicans virulence by bacterial biofilms on titanium surfaces. Biofouling 2016, 32, 123-134. [CrossRef] [PubMed]

56. Kim, H.W.; Knowles, J.C.; Salih, V.; Kim, H.E. Hydroxyapatite and flour-hydroxyapatite layered film on titanium processed by a sol-gel route for hard-tissue implants. J. Biom. Mater. Res. Part B Appl. Biomater. 2004, 71, 66-76. [CrossRef] [PubMed]

57. Ciobanu, C.S.; Constantin, L.V.; Predoi, D. Structural and physical properties of antibacterial Ag-doped nano-hydroxyapatite synthesized at $100{ }^{\circ} \mathrm{C}$. Nanoscale Res. Lett. 2011, 6, 613. [CrossRef] [PubMed]

58. Iconaru, S.L.; Prodan, A.M.; Buton, N.; Predoi, D. Structural characterization and antifungal studies of Zinc-doped hydroxyapatite coatings. Molecules 2017, 22, 604. [CrossRef] [PubMed]

59. Tektronix. Available online: http:/ / www.tek.com (accessed on 5 August 2018).

60. Gallagher, A.J.; Gundle, R.; Beresford, N.J. Isolation and culture of bone forming cells (osteoblasts) from human bone. Hum. Cell Cult. Protoc. 1996, 2, 233-263.

61. M07-A9 Methods for Dilution Antimicrobial Susceptibility Tests for Bacteria That Grow Aerobically; Approved Standard-Ninth Edition; Clinical and Laboratory Standards Institute: Wayne, PA, USA, 2012.

62. Lutterotti, L. Total pattern fitting for the combined size-strainstress-texture determination in thin film diffraction. Nucl. Instrum. Meth. B 2010, 268, 334-340. [CrossRef]

63. M100-S22 Performance Standards for Antimicrobial Susceptibility Testing; Twenty-Second Informational Supplement; Clinical and Laboratory Standards Institute: Wayne, PA, USA, 2012.

64. Dukhin, A.S.; Goetz, P.J. Ultrasound for Characterizing Colloids Particle Sizing, Zeta Potential, Rheology; Studies in Interface Science; Elsevier: Amsterdam, The Netherlands, 2002; Volume 15.

65. Teng, S.H.; Lee, E.J.; Park, C.S.; Choi, W.Y.; Shin, D.S.; Kim, H.E. Bioactive nanocomposite coatings of collagen/hydroxyapatite on titanium substrates. J. Mater. Sci. Mater. Med. 2008, 19, 2453-2461. [CrossRef] [PubMed]

66. Ciobanu, C.S.; Groza, A.; Iconaru, S.L.; Popa, C.L.; Chapon, P.; Chifiriuc, M.C.; Hristu, R.; Stanciu, G.A.; Negrila, C.C.; Ghita, R.V.; et al. Antimicrobial activity evaluation on silver doped hydroxyapatite/polydimethylsiloxane composite layer. BioMed Res. Int. 2015, 2015, 926513. [CrossRef] [PubMed]

67. Depypere, F.; Van Oostveldt, P.; Pieters, J.G.; Dewettinck, K. Quantification of microparticle coating quality by confocal laser scanning microscopy (CLSM). Eur. J. Pharm. Biopharm. 2009, 73, 179-186. [CrossRef] [PubMed]

68. Patel, D.V.; McGhee, C.N. Contemporary in vivo confocal microscopy of the living human cornea using white light and laser scanning techniques: A major review. Clin. Exp. Ophthalmol. 2007, 35, 71-88. [CrossRef] [PubMed]

69. Pawley, J.B. Handbook of Biological Confocal Microscopy, 3rd ed.; Springer: Boston, MA, USA, 2006; pp. $20-42$. ISBN 0-387-25921-X.

70. Rai, M.; Yadav, A.; Gade, A. Silver nanoparticles as a new generation of antimicrobials. Biotechnol. Adv. 2009, 27, 76-83. [CrossRef] [PubMed]

71. Miranda, M.; Fernandez, A.; Lopez-Esteban, S.; Malpartida, F.; Moya, J.S.; Torrecillas, R. Ceramic/metal biocidal nanocomposites for bone-related applications. J. Mater. Sci. Mater Med. 2012, 23, 1655-1662. [CrossRef] [PubMed]

72. Zamperini, C.A.; André, R.S.; Longo, V.M.; Mima, E.G.; Vergani, C.E.; Machado, A.L.; Varela, J.A.; Longo, E. Antifungal Applications of Ag-Decorated Hydroxyapatite Nanoparticles. J. Nanomater. 2013, 2013, 174398. [CrossRef]

(C) 2018 by the authors. Licensee MDPI, Basel, Switzerland. This article is an open access article distributed under the terms and conditions of the Creative Commons Attribution (CC BY) license (http://creativecommons.org/licenses/by/4.0/). 